\title{
Heterozygous $\mathrm{C} 2$ deficiency associated with angioedema, myasthenia gravis, and systemic lupus erythematosus
}

\author{
J EFTHIMIOU, D D'CRUZ, P KAPLAN, AND D ISENBERG \\ From the Department of Medicine, University College London School of Medicine, The Rayne Institute \\ University Street, London
}

SUMMARY We describe a patient with myasthenia gravis, systemic lupus erythematosus, and angioedema associated with heterozygous complement factor 2 (C2) deficiency. The significance of this association is controversial, though the association of $\mathrm{C} 2$ deficiency with certain histocompatibility antigens suggests possible linkage to immune response genes. To our $\infty$ knowledge this is the first report of heterozygous $\mathrm{C} 2$ deficiency in association with this combination of 'autoimmune' disorders, and we discuss the aetiological implications.

The coexistence of myasthenia gravis and systemic lupus erythematosus (SLE) is well recognised, ${ }^{1-5}$ though the association of these two conditions with angioedema has only once previously been reported. ${ }^{5}$ Homozygous and, less commonly, heterozygous deficiency of complement factor 2 (C2) is also recognised in association with $\mathrm{SLE}^{6-8}$ but has not previously been described in association with myasthenia gravis. We report on a patient with angioedema, myasthenia gravis, and SLE who had heterozygous $\mathrm{C} 2$ deficiency.

\section{Case history}

A 36 year old Caucasian woman known to have myasthenia gravis was admitted to hospital with a one year history of intermittent polyarthritis involving the hands, knees, and ankles, Raynaud's phenomenon, and urticarial rashes associated with swelling of her lips and tongue.

At the age of 16 years she presented with bilateral ptosis, dysarthria, and dysphagia. Myasthenia gravis was confirmed by electromyography, and she responded well to treatment with pyridostigmine.

Accepted for publication 9 October 1985

Correspondence to Dr J Efthimiou, Department of Medicine, The Rayne Institute, University Street, London WC1E 6JJ.
Examination showed swollen tender metacarpophalangeal and ankle joints, with an urticarial rash over her arms. Auscultation of her chest $\vec{O}$ showed bilateral late inspiratory crepitations over both lung bases.

She had an erythrocyte sedimentation rate (ESR) of $58 \mathrm{~mm} / 1 \mathrm{st} \mathrm{h}$ (Westergren), antinuclear antibody (ANA) titre of $1 / 640$, with a diffuse (homogeneous) pattern, DNA antibody titre of $38 \mathrm{U} / \mathrm{ml}$ (normal 3 $<25 \mathrm{U} / \mathrm{ml}$ ), skeletal muscle antibody, and acetylcholine receptor antibody titre of $4 \times 10^{-10} \mathrm{~mol} / \mathrm{l}$ (normal $\left.<2 \times 10^{-10} \mathrm{~mol} / \mathrm{l}\right)$. The $\mathrm{C} 2$ level was $45 \%$ of $\circ$ normal, the total haemolytic complement $\left(\mathrm{CH}_{50}\right)$ 궁 $50 \%$ of normal, and increased levels of circulating IgG and IgM immune complexes (determined by C1q binding) were detected. Histocompatibility o antigen (HLA) typing showed that she was HLA-A1 N and B8 positive. The full blood count (including N white cell count and lymphocyte number), urea, $\sigma$ electrolytes, creatinine clearance, and levels of complement factors $\mathrm{C} 3$ and $\mathrm{C} 4$ and $\mathrm{C} 1$ esterase $\stackrel{0}{\mathrm{C}}$ inhibitor were normal.

The chest radiograph showed reticulonodular + shadowing over both lower zones. A computed tomographic scan of the thorax disclosed evidence $\overrightarrow{\mathbb{D}}$ of a thymoma. Transbronchial lung biopsy showed $\frac{\rho}{\mathbb{P}}$ fibrosis and chronic inflammation of the alveolar walls consistent with fibrosing alveolitis. 
A diagnosis of SLE, angioedema, myasthenia gravis, and heterozygous $\mathrm{C} 2$ deficiency was made. A healthy 11 year old son who was HLA-A1 and B8 positive was also found to have a reduced $\mathrm{C} 2$ level ( $60 \%$ of normal) and an ANA titre of $1 / 80$, with a diffuse (homogeneous) pattern. The mother, one sister, and two daughters of our patient all had normal levels of $\mathrm{C} 2$. Her father and husband were not available for study.

She was initially treated with naproxen for the polyarthritis and chlorpheniramine and cimetidine for the urticaria and angioedema and made a good response. Three months after cimetidine treatment was stopped she was readmitted with a more extensive urticarial rash involving her arms, abdomen, and neck, with swelling of her lips and tongue. She was treated with subcutaneous adrenaline, intravenous chlorpheniramine, and hydrocortisone, which resulted in prompt clearance of the angioedema. Cimetidine therapy was recommenced and prednisolone (30 mg daily) added, with complete resolution of the polyarthritis.

At follow up one year later while still taking prednisolone ( $7.5 \mathrm{mg}$ on alternate days) she remained asymptomatic. Investigations at that time showed the ESR was $21 \mathrm{~mm} / 1 \mathrm{st} \mathrm{h}$, the ANA titre $1 / 80$, and the $\mathrm{C} 2$ level $51 \%$ of normal.

\section{Discussion}

Homozygous C2 deficiency is the commonest inherited complement factor deficiency. ${ }^{9}$ Homozygous $\mathrm{C} 2$ deficiency occurs in approximately one in 10000 to one in 40000 of the normal population and heterozygous $\mathrm{C} 2$ deficiency (i.e., with $\mathrm{C} 2$ levels of approximately $50 \%$ of normal) in up to $2 \%$ of the population. ${ }^{1011}$ The gene determining C2 deficiency, i.e., C2D, appears to be inherited as an autosomal codominant with a marked predominance in females, who show a significantly higher incidence of rheumatic diseases than males (i.e., $25.7 \%$ of affected females compared with $4 \cdot 2 \%$ of affected males). ${ }^{12}$ Both homozygous and heterozygous $\mathrm{C} 2$ deficiencies are known to occur in association with SLE. ${ }^{7-913}$ A large number of diseases have been linked with homozygous C2 deficiency, including anaphylactoid purpura, undiagnosed arthritis, dermatomyositis, chronic vasculitis, Hodgkin's disease, idiopathic membranous glomerulonephritis, and recurrent infections, ${ }^{7-9} 13$ though many individuals (approximately $40 \%$ ) may have none of these problems and appear perfectly healthy. ${ }^{13}$ Heterozygous $\mathrm{C} 2$ deficiency has also been associated with a variety of rheumatic and non-rheumatic disorders, including juvenile rheumatoid arthritis, arthralgia of unknown aetiology, rheumatoid arthritis, chronic glomerulonephritis, psoriasis, and recurrent infections. ${ }^{10} 1214$

SLE is known to occur in association with myasthenia gravis, ${ }^{1-5}$ but there has been only one previous report of these two conditions in association with urticaria. ${ }^{5}$ In addition, SLE and particularly SLE-like syndromes are recognised to occur in association with hereditary angioedema due to $\mathrm{C} 1$ esterase inhibitor (C1 EI) deficiency, ${ }^{14 a-17}$ as well as with acquired complement deficiency states. ${ }^{12} 13$ Furthermore, patients with hereditary C1 EI deficiency, who may show a marked depression of $\mathrm{C} 2$ and $\mathrm{C} 4$ levels both during and between attacks of angioedema, ${ }^{13}{ }^{16-18}$ have been known to develop SLE and discoid lupus erythematosus. ${ }^{14 a}{ }^{15}$ In a twin study of hereditary angioedema one of a pair of female twins showed a marked deficiency of C2 and C4 levels and later developed SLE. ${ }^{17}$

Myasthenia gravis has not previously been described in association with depression or deficiency of the early complement components. A genetic susceptibility to myasthenia gravis, however, is suggested by the finding of an association with HLA-A1 and B8. ${ }^{19}$ In addition, there is a close positive linkage between the gene determining $\mathrm{C} 2$ deficiency and the HLA genes A10, B8, and Dw2, ${ }^{12} 2021$ and these genes also occur in close association with SLE and SLE-like disorders. ${ }^{12}$

It seems unlikely that the association of $\mathrm{C} 2$ deficiency and SLE, two relatively rare conditions, is purely coincidental. Deficiency of early complement components is likely to compromise the host's ability to eliminate antigens and this may give rise to immune complex mediated disease. ${ }^{9} 13$ There is some evidence that persistent infection with a virus may produce lupus-like syndromes, and that deficiency of factors required to form $\mathrm{C} 3$ convertase could lead to a reduced ability to eliminate the virus from the serum, thus leading to immune complex formation and disease. ${ }^{922}{ }^{23}$ Another possibility is that the complement deficiency is a marker for a closely linked genetic locus which itself determines the disease. ${ }^{9}$ This argument is supported by the studies of Glass $e t$ al $^{10}$ and could apply to our patient, who has a heterozygous $\mathrm{C} 2$ deficiency and is HLA-A1 and B8 positive. Together, these determinants may be markers for a genetic susceptibility to the development of SLE, angioedema, and myasthenia gravis.

We have described a patient with heterozygous C2 deficiency who developed angioedema, myasthenia gravis, and SLE, and was HLA-A1 and B8 positive. To our knowledge this is the first report of C2 deficiency associated with myasthenia gravis, though SLE and angioedema are well known to occur with $\mathrm{C} 2$ deficiency. Further similar reports 
may throw more light on the relationship of complement factor deficiencies and the development of autoimmune and other immunologically mediated diseases.

\section{References}

1 Goeldin H, Robbins W C. A patient with myasthenia gravis, thymoma and lupus nephritis. Arthritis Rheum 1963; 6: 272-4.

2 Makela T E. Myasthenia gravis and systemic lupus erythematosus. Acta Med Scand 1964; 175: 777-80.

3 Mackechnie H L N, Squires A H, Platts M, Pruzanski W. Thymoma, myasthenia gravis, erythroblastic anaemia and systemic lupus erythematosus in one patient. Can Med Assoc J 1973; 109: 733-8.

4 Calabrese L H, Back J-F, Curric T, Vidt D, Clough J, Krakauer R S. Development of systemic lupus erythematosus after thymectomy for myasthenia gravis. Arch Intern Med 1981; 141: 253-5.

5 Darley C I L, Munro D D. Myasthenia gravis, systemic lupus erythematosus and urticaria. Proc $R$ Soc Med 1977; 70: 734-7.

6 Agnello V, deBracco M M E, Kunkel H G. Hereditary C2 deficiency with some manifestations of systemic lupus erythematosus. J Immunol 1972; 108: 837-40.

7 Day N K, Geiger H, McLean R, Michael A, Good R A. C2 deficiency: development of lupus erythematosus. J Clin Invest 1973; 52: 1601-7.

8 Gibson D J, Glass D, Carpenter C B, Schur P H. Hereditary C2 deficiency: diagnosis and HLA gene complex associations. $J$ Immunol 1976; 116: 1065-70.

9 Lachmann P J. Clinical effects of complement deficiency. In: Peters D K, ed. Advanced Medicine Series. 12th Symposium on Advanced Medicine. London: Pitman Medical, 1976.

10 Glass D, Raum D, Gibson D, Stillman J S, Schur P H. Inherited deficiency of the second component of complement. $J$ Clin Invest 1976; 58: 853-61.

11 Fu S M, Stern R, Kunkel H G, et al. LD-7a association with C2 deficiency in five of six families. In: Dausset J, ed. Histocompatibility testing. Copenhagen: Munksgaard, 1975: 933-6.

12 Agnello V. Complement deficiency states. Medicine (Baltimore) 1978; 57: 1-23.
13 Agnello V. Association of systemic lupus erythematosus and SLE-like syndromes with hereditary and acquired complement deficiency states. Arthritis Rheum 1978; 21: 146-52.

14 McCarty D J, Tan E M, Zvaifler N J, Koethe S, Duquesnoy R J. Serological studies in a family with heterozygous $\mathrm{C} 2$ deficiency. Am J Med 1981; 71: 945-8.

$14^{\mathrm{a}}$ Kohler P F, Percy J, Campion W N, Smyth C J. Hereditary angioedema and 'familial' lupus erythematosus in identical twin boys. Am J Med 1974; 56: 406-11.

15 Donaldson V H, Hess E V, McAdams A J. Lupuserythematosus like disease in three unrelated women with hereditary angioneurotic oedema. Ann Intern Med 1977; 86: 312-3.

16 Donaldson V H, Stroud R M. Genetic defects of complement. In: Brent L, Holbrow J, eds. Progress in immunology II New York: American Elsevier, 1974; I: 288.

17 Rosenfeld G B, Partridge R E H, Bartholomew W, et al. Hereditary angioneurotic oedema (HANE) and systemic lupus erythematosus (SLE) in one of identical twin girls [Abstract]. $J$ Allergy Clin Immunol 1974; 47: p 68.

18 Donaldson V H, Merler E, Rosen F S, Kretschoner K W, Lepow I H. A polypeptide kinin in hereditary angioneurotic oedema plasma: role of complement in its formation. $J$ Lab Clin Med 1970; 76: 986A.

19 Behan B O. Immune disease and HLA association with myasthenia gravis. J Neurol Neurosurg Psychiatry 1980; 43: 611-21.

20 Fu S M, Kunkel H G, Brusman H P, Allen J, Fotino F H. Evidence for linkage between HLA histocompatibility genes and those involved in the synthesis of the second component of complement. J Exp Med 1975; 142: 495-506.

21 Gibson D J, Glass D, Carpenter C B, Schur P H. Hereditary C2 deficiency: diagnosis and HLA gene complex associations. $J$ Immunol 1976; 116: 1065-70.

22 Joseph B S, Cooper N R, Oldstone M B. Immunological injury of cultured cells infected with measles virus: role of $\mathrm{IgG}$ antibody and the alternative complement pathway. $J$ Exp Med 1975; 141: 761-4.

23 Cooper N R, Jensen F C, Welsh R M, Oldstone M B A. Lysis of RNA tumor viruses by human serum: direct antibody independent triggering of the classical complement pathway. J Exp Med 1976; 144: 970 